16. Сенчина Н.П. Поиски коренной платиноидной минерализации путём изучения естественных электрических полей и ореолов рассеяния подвижных форм нахождения химических элементов / Автореф. дисс. к.г.-м.н. 2017. С.-Пб. Горный университет. Санкт-Петербург. 22 с.

17. Харченко С.В. К вопросу о применении гармонического анализа при количественной характеристике рельефа //Геоморфология. 2017. №2. С.14-24. 18. Хибинский щелочной массив / Материалы по геологии и полезным ископаемым Северо-Запада РСФСР. Л.: «Недра», 1972. 176 с.

19. Штокаленко М.Б., Путиков О.Ф., Алексеев С.Г., Вешев С.А., Ворошилов Н.А. Оценка параметров струйной миграции по ширине ореола вторично закрепленных форм химических элементов // Геофизика. 2006. № 4. С. 55-60.

20. Штокаленко М.Б., Алексеев С.Г., Вешев С.А., Ворошилов Н.А., Маргович Е.Г., Путиков О.Ф. Механизмы формирования наложенных ореолов, фиксируемых геоэлектрохимическими и атмохимическими методами // Российский геофизический журнал. 2009. № 47-48. С. 33-50.

\title{
МАТЕМАТИЧЕСКОЕ МОДЕЛИРОВАНИЕ ПРИРОДНЫХ И ХИМИКО-ТЕХНОЛОГИЧЕСКИХ СИСТЕМ
}

Каржавин В.К.

https://doi.org/10.31241/MIEN.2018.14.22

Геологический институт КНЦ РАН, Апатиты, karzhavin@geoksc.apatity.ru

\section{Аннотация}

Моделирование на ЭВМ служит не просто способом наглядного и достоверного отображения фактических данных, но и является инструментом получения новой информации. На этом фоне проявляются основные тенденции физикохимического моделирования природных и химико-технологических систем. Каждая исследуемая система должна иметь реальные границы термодинамических параметров и определяться тем необходимым и достаточным набором независимых компонентов, с помощью которых можно моделировать всё многообразие природного процесса или переработки минерального сырья. Основой таких исследований является чёткое формулирование и грамотная постановка задачи моделирования, корректный выбор математической модели и т.д.

\section{Ключевые слова}

Математическое моделирование, минимизации свободной энергии Гиббса, термобарометрия, минеральное сырьё, метод равновесные условия, система, давление, температура.

Интенсивное развитие математических дисциплин последних десятилетий способствовали существенному влиянию и воздействию на другие науки. Это, в свою очередь, позволило значительно расширить возможности и повысить эффективность проводимых научных исследований. Математи- 
ческое моделирование стало составной частью исследований ряда сложных проблем. Построение математической модели во многом зависит от её целевого назначения, свойств объекта и т.д. Самой ответственной частью при использовании того или иного метода исследования является выбор структуры модели. При этом требуется не, сколько знание математики, а глубокое понимание сущности описываемого явления. В каждом конкретном случае математическую модель создают исходя из целевой направленности процесса и задач исследования, с учётом требуемой точности решения и достоверности используемых данных.

Метод математического моделирования основан на тождественности уравнений, описывающих процессы модели или исследуемого явления. Подобный подход даёт возможность, абстрагируясь от неизученной сущности процесса, устанавливать функциональную связь между входными и выходными параметрами систем и решать задачу оптимизации на основе математико-статистического описания.

Наиболее эффективное применение достижений физики и химии для анализа динамических систем связано с методами термодинамического анализа. Это определяется соответствующей строгостью термодинамических построений и даёт возможность делать широкие обобщения, позволяет исследовать явление независимо от его интерпретации в виде структурногенетических схем. Например, их современное приложение в геологии это сумма частных решений при общем контроле со стороны геологических данных. Математическое моделирование позволяет воспроизводить определённым образом подобранные условия физико-химической ситуации для изучения взаимоотношений между компонентами в сложных системах на основе термодинамических методов исследования. Ярким примером этому является математическое моделирование на ЭВМ природных процессов, базирующихся на основе экспериментальной, эмпирической и термодинамической информации.

Термодинамическим исследованиям отводится важная роль при анализе процессов, сопровождаемых химическими и фазовыми превращениями в широком интервале температур и давлений. Для равновесных или локально равновесных процессов расчёт параметров состояния позволяет с относительно высокой точностью моделировать реальные условия и представлять информацию, которую пока невозможно произвести экспериментальным путём в лабораторных условиях. Равновесные расчеты (численный эксперимент) отражают лишь качественные тенденции. Условие равновесия в системе, приводящее к задаче условной минимизации может быть представлено в эквивалентной форме, как условие определения степени протекания реакций в сложной системе. Для исследования промышленного процесса необходимо использовать термодинамику необратимых процессов через решение систем нелинейных уравнений с ограничениями в виде равенств и неравенств, которые часто не имеют точного аналитического решения. 
Принято считать, что состав и термодинамические свойства равновесных продуктов однозначно зависят от элементарного состава, температуры и давления [2, 3]. Автором показано, что система уравнений констант равновесия и материального баланса имеет одно единственное решение, отвечающее физическому смыслу. Это позволяет широко использовать термодинамические методы исследования для решения многочисленных задач. Например, оценка температуры и давления протекающих процессов в природной среде, при которых происходило образование минералов, является важной задачей для прогнозирования протекающих в природных условиях постмагматических (метаморфических) процессов. Для данной цели исследуется химический состав совместно присутствующих в природном образце минералов, и осуществляют расчёт на основании констант равновесия химических реакций. Наличие равновесия в исследуемой природной системе, позволяет оценить исходные Р-Т параметры процессов образования минералов при магматических, метаморфических, метасоматических, гидротермальных и рудообразующих процессах.

Исследование природы метаморфических и метасоматических преобразований пород рудоносных интрузивов предполагается проводить при комплексном использовании современных методов парагенетического анализа минеральных ассоциаций, электронно-микрозондового изучения составов минеральных фаз, оценок термодинамических и физико-химических условий их формирования и реконструкции Р-Т- $\tau$ трендов метаморфической эволюции. Для данной цели используется термобарометрические методы вариантов программы TWQ [14], оснащенной внутренне совместимой базой данных термодинамических величин химических соединений и твердых растворов минералов, и последующая оценка состава летучих компонентов и флюидного режима в целом для установленных равновесных условий, используя метод минимизации свободной энергии Гиббса $[4,11]$. Такой подход в планируемых исследованиях представляется перспективным для поиска равновесных составов в природной системе, а также позволяет более обосновано оценивать Р-Т условия, в которых формировался данный парагенезис.

Использование недостаточно полной информации при определении термодинамических условий образования природной системы может повлиять на достоверность результатов исследования. Правильность выбора количества компонентов в системе должна обеспечить возможность составления всех реакций, которые позволят получить объективную информацию. Однако при традиционном подходе в расчётах учитывается иногда только основные химические соединения, которые могут принимать участие в реакциях.

Компьютерный расчет химических взаимодействий действительно имеет ряд несомненных преимуществ перед трудоемким модельным экспериментом. Основой физико-химического моделирования является описание объекта и процессов, протекающих в нем с изменением его свойств, а также состава компонентов. При этом термодинамическое моделирование позво- 
ляет проследить поэтапный (например, в зависимости от Р-Т параметров) механизм преобразования в гомогенных и гетерогенных системах компонентов твердой фазы и состава флюида. Именно поэтому математический аппарат химической термодинамики позволяет, на основе термодинамических величин, проследить химические взаимодействия в многокомпонентных и многофазных системах.

Известно, что превращение исходных веществ в продукты химических реакций большинства исследуемых процессов осуществляется через ряд элементарных реакций, о механизме которых можно делать лишь различные предположения. Поэтому для расчёта векторного состава независимых компонентов создаваемых мультисистем проводится путём грамотного перерасчёта результатов химического анализа исследуемого объекта. На данном этапе подготовки необходимо учитывать наличие возможных реакций окисления-восстановления, растворения, гидролиза, комплесообразования, ионного обмена и т.д. Накопленный нами за годы исследований фактический материал, позволяет по новому осветить ряд вопросов: по минералогии, термодинамическим условиям формирования минеральных парагенезисов в расслоенных горизонтах, физико-химического моделирования химико-технологических систем и переработки природного сырья.

I. Апатит. Были изучены и получены результаты численного моделирования на ЭВМ возможности получения плавленых кальциево-магниевых фосфатов $[5,10]$. Изучаемый процесс был описан системой из 11 независимых компонентов: Si-Al-Fe-Ca-Mg-K-P-F-C-H-O. В качестве объекта исследования был принят апатит Ковдорского месторождения. Данный природный объект представляет собой сложную смесь, содержащую фтор-, гидроксил-, карбонат- и оксиапатит, т.е. гидроксилоксифторапатит с незначительной долей его карбонатсоставляющей. Целью исследования явилось определение условий образования лимоннорастворимого $\alpha-\mathrm{Ca}_{3}\left(\mathrm{PO}_{4}\right)_{2}$. Основой для проведения математического моделирования использовались искусственные составы шихты Ковдорского апатита в присутствии различных добавок: доломита, флогопита, диопсида и их смесей. Исследуемый температурный интервал нагревания составлял 800-1400 ${ }^{\circ} \mathrm{C}$. В результате проведённых физико-химических расчётов при помощи ЭВМ было установлено, что лимоннорастворимые $\alpha-$ и $\beta-\mathrm{Ca}_{3}\left(\mathrm{PO}_{4}\right)_{2}$ действительно образуются за счёт разложения $\mathrm{Ca}_{10}\left(\mathrm{PO}_{4}\right)_{2} \mathrm{CO}_{3}, \mathrm{Ca}_{10}\left(\mathrm{PO}_{4}\right)_{2} \mathrm{O}$, и $\mathrm{Ca}_{10}\left(\mathrm{PO}_{4}\right)_{2}(\mathrm{OH})_{2}$ (рис. 1). Однако, в этом же температурном интервале фторапатит, присутствующий в сложной шихте, не разлагается, что подтвердилось и результатами проведённых лабораторных экспериментов.

Таким образом, получаемый по данной методике «плавленый кальциевомагниевый фосфат» как удобрение будет засорять поля нерастворимым фторапатитом (его ПР равен 115.6 [12]). Поэтому данный метод получения плавленых кальциево-магниевых фосфатов не был рекомендован для производства промышленностью. 


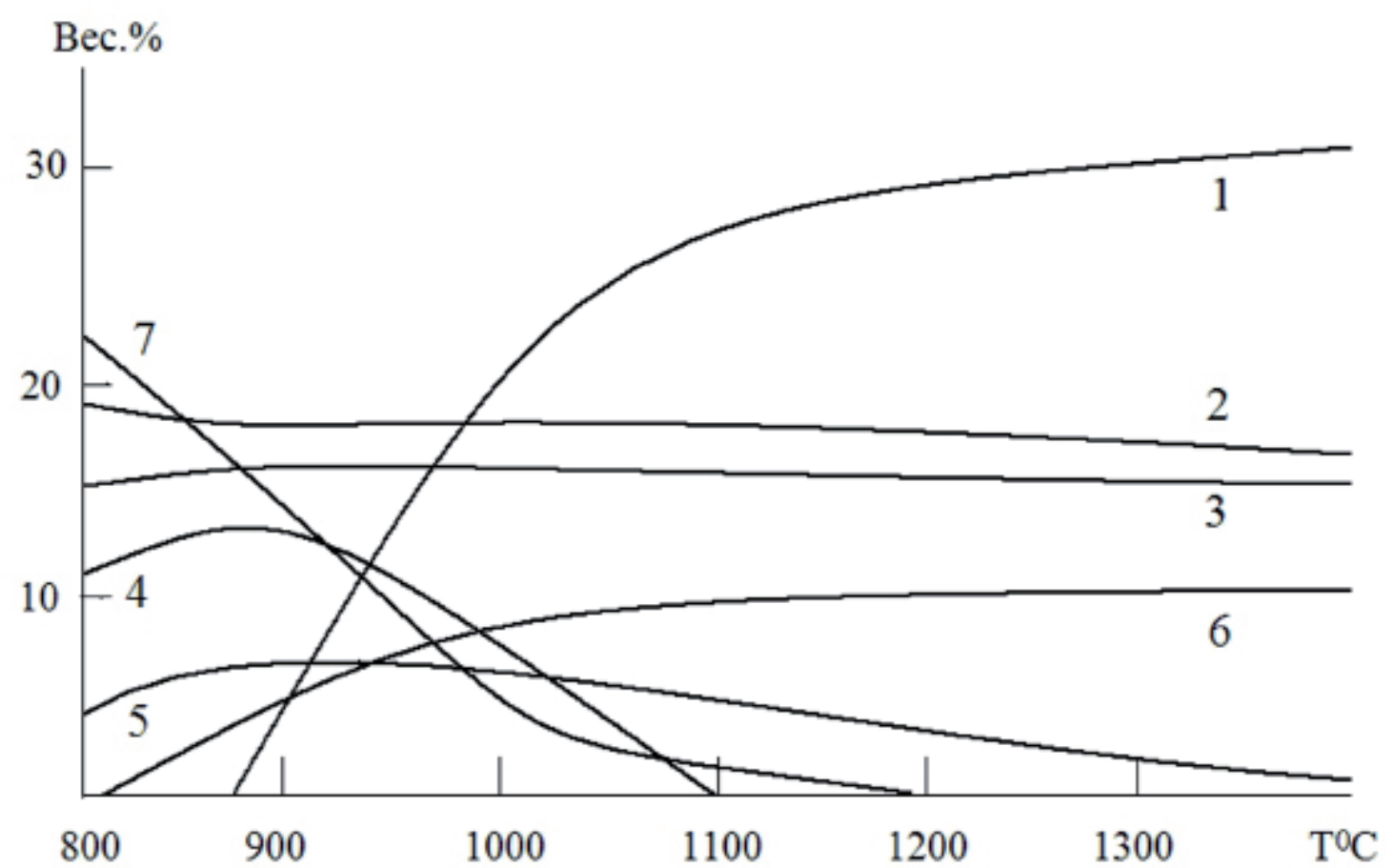

Рис. 1. Зависимость содержания компонентов от температуры нагревания смесей фосфорсодержамего соединения с диопсидом. Фазы: $1-\alpha-u \beta$ - $\mathrm{Ca}_{3}\left(\mathrm{PO}_{4}\right)_{2}$; $2-\mathrm{Mg}_{2} \mathrm{SiO}_{4} ; 3-\mathrm{Ca}_{10}\left(\mathrm{PO}_{4}\right)_{2} \mathrm{~F}_{2} ; 4-\mathrm{Ca}_{10}\left(\mathrm{PO}_{4}\right)_{2} \mathrm{CO}_{3} ; 5-\mathrm{Ca}_{10}\left(\mathrm{PO}_{4}\right)_{2} \mathrm{O} ; 6-\mathrm{CaMgSiO}_{4}$; $7-\mathrm{Ca}_{10}\left(\mathrm{PO}_{4}\right)_{2}(\mathrm{OH})_{2}$.

II. Платиноиды. Оценка состава флюида, равновесного с твёрдой платино-палладиевой фазой, осуществлялась путём реализации мультисистем для каждой метаморфической зоны. Для теоретических исследований были созданы физико-химические модельные мультисистемы. Например, исходная мультисистема для образцов Панского массива содержала 18 независимых компонентов (элементы): Si-Al-Fe-Ca-Mg-Na-K-Cu-Ni-Pd-Pt-S-SeTe-Ti-C-H-O. Расчётная матрица мультисистемы была составлена из 34 зависимых компонентов силикатно-сульфидных фаз и флюидной фазы, включающей следующие компоненты: $\mathrm{H}_{2} \mathrm{O}, \mathrm{H}_{2}, \mathrm{O}_{2}, \mathrm{CO}, \mathrm{CO}_{2}, \mathrm{~S}_{2}, \mathrm{SO}_{2}, \mathrm{H}_{2} \mathrm{~S}, \mathrm{Se}_{2}, \mathrm{SeO}_{2}$, $\mathrm{H}_{2} \mathrm{Se}, \mathrm{Te}_{2}, \mathrm{TeO}_{2}, \mathrm{H}_{2} \mathrm{Te}, \mathrm{CH}_{4}, \mathrm{C}_{2} \mathrm{H}_{6}[1,6,7]$.

В результате проведённого исследования было установлено, что для начального этапа раннего автометаморфического преобразования пород с пироксен-куммингтонитовыми парагенезисами (Opx-Cum №1) определены следующие термодинамические параметры: $\mathrm{T}=623^{\circ} \mathrm{C}$ и $\mathrm{P}=6.15$ кбар. Протекающие в данной системе химические реакции являются равновесными, например, при $623^{\circ} \mathrm{C}$ и давлении 6.15 кбар (рис. 2):

Последующая оценка $\mathrm{P}$ - Т параметров метаморфических преобразований пород определялась аналогично при помощи программы TWQ. Так ранняя плагиоклаз-актинолитовая ассоциация (Pl-Act № 2) осуществлялась при $\mathrm{T}=382^{\circ} \mathrm{C}$ и $\mathrm{P}=1.65$ кбар. А парагенезис (Pl-Act-Ts № 3) при $\mathrm{T}=398^{\circ} \mathrm{C}$ и $\mathrm{P}=2.6$ кбар. 


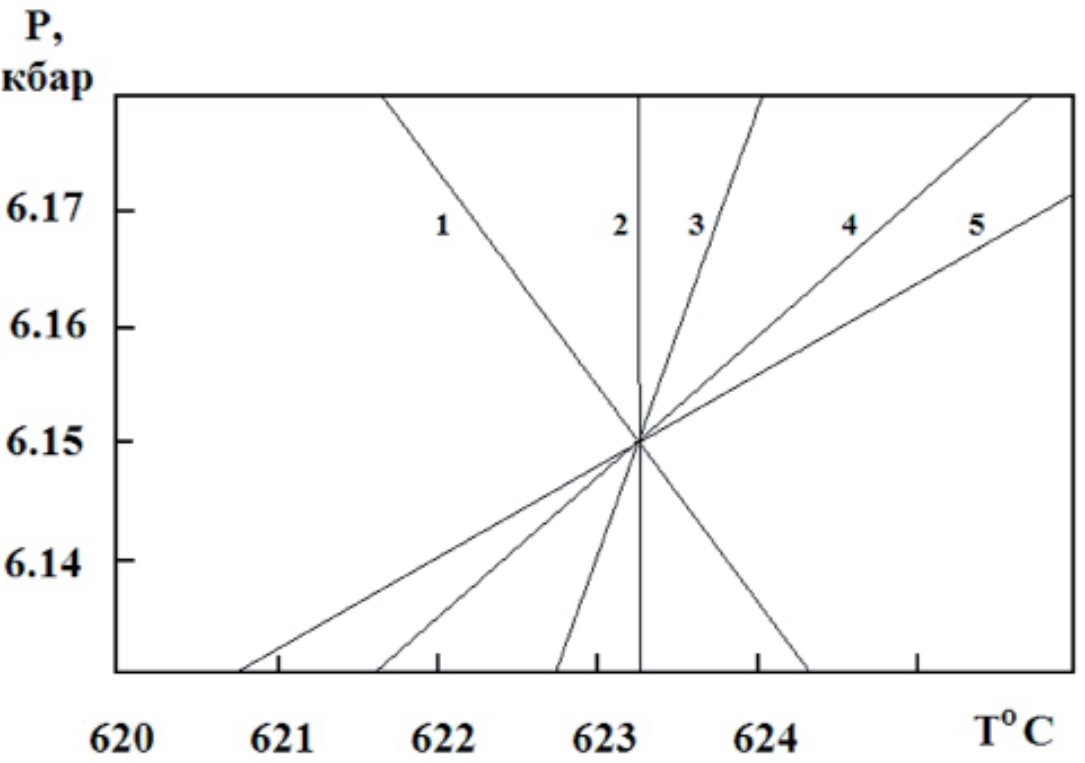

Рис. 2. Оиенка Р-Т параметров автометаморфических ассоцииций (Орх-Сит).

1) $9 \mathrm{An}+3 \mathrm{Cum}+3 \mathrm{Di}+2 \mathrm{Mgt}=12 \mathrm{En}+3 \mathrm{Fs}+6 \mathrm{CzO}+\mathrm{O}_{2}$

2) $6 \mathrm{Cum}+2 \mathrm{Mgt}=21 \mathrm{En}+3 \mathrm{Fs}+6 \mathrm{H}_{2} \mathrm{O}+\mathrm{O}_{2}$

3) $\mathrm{Cum}+2 \mathrm{CzO}=3 \mathrm{An}+\mathrm{Di}+3 \mathrm{En}+2 \mathrm{H}_{2} \mathrm{O}$

4) $21 \mathrm{An}+7 \mathrm{Di}+2 \mathrm{Mgt}+8 \mathrm{H}_{2} \mathrm{O}=\mathrm{Cum}+3 \mathrm{Fs}+14 \mathrm{CzO}+\mathrm{O}_{2}$

5) $18 \mathrm{An}+6 \mathrm{Di}+2 \mathrm{Mgt}+6 \mathrm{H}_{2} \mathrm{O}=3 \mathrm{En}+3 \mathrm{Fs}+12 \mathrm{CzO}+\mathrm{O}_{2}$

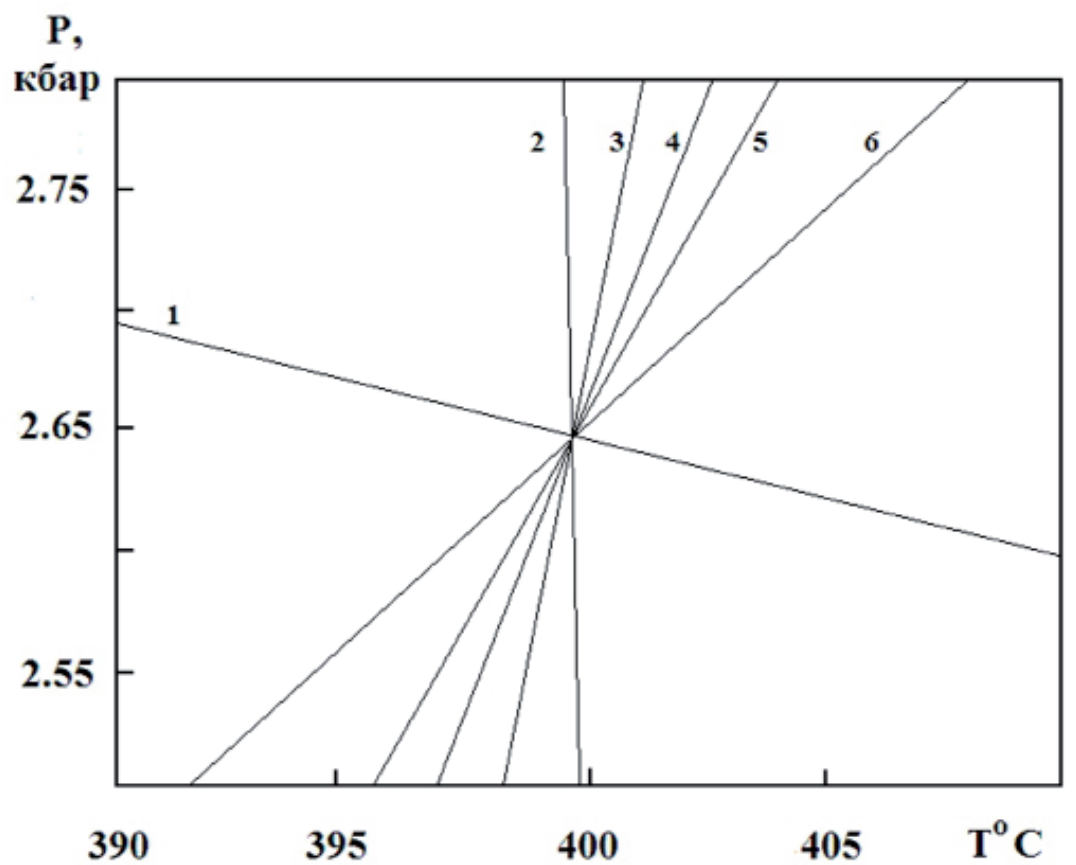

Рис. 3. Оиенка P-T параметров автометаморфических ассощиищий (Pl-Act-Ts).

1) $5 \mathrm{Ann}+14 \mathrm{aQz}+5 \mathrm{Tsc}+12 \mathrm{cZo}=5 \mathrm{Phl}+28 \mathrm{An}+3 \mathrm{Act}+8 \mathrm{H}_{2} \mathrm{O}$

2) $4 \mathrm{An}+2 \mathrm{Mt}+2 \mathrm{Phl}+4 \mathrm{aQz}+2 \mathrm{H}_{2} \mathrm{O}=2 \mathrm{TsC}+2 \mathrm{Ann}+\mathrm{O}_{2}$

3) $12 \mathrm{cZo}+30 \mathrm{aQz}+3 \mathrm{Phl}+8 \mathrm{Mt}=3 \mathrm{Act}+3 \mathrm{Ann}+12 \mathrm{An}+3 \mathrm{Tsc}+4 \mathrm{O}_{2}$

4) $12 \mathrm{cZo}+42 \mathrm{aQz}+9 \mathrm{Phl}+14 \mathrm{Mt}+6 \mathrm{H}_{2} \mathrm{O}=3 \mathrm{Act}+9 \mathrm{Ann}+9 \mathrm{Tsc}+7 \mathrm{O}_{2}$

5) $24 \mathrm{cZo}+48 \mathrm{aQz}+10 \mathrm{Mt}=6 \mathrm{Act}+36 \mathrm{An}+6 \mathrm{H}_{2} \mathrm{O}+5 \mathrm{O}_{2}$

6) $6 \mathrm{Act}+84 \mathrm{An}+14 \mathrm{Mt}+24 \mathrm{Phl}+30 \mathrm{H}_{2} \mathrm{O}=24 \mathrm{cZo}+24 \mathrm{Tsc}+24 \mathrm{Ann}+7 \mathrm{O}_{2}$ 
PdS

$\mathbf{M 0 . T b} / \mathbf{K r}$

PtS

$-5$

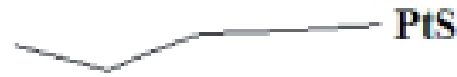

$-6$

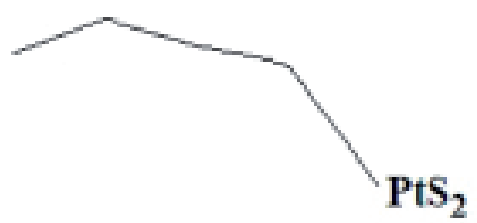

$-7$

Pt
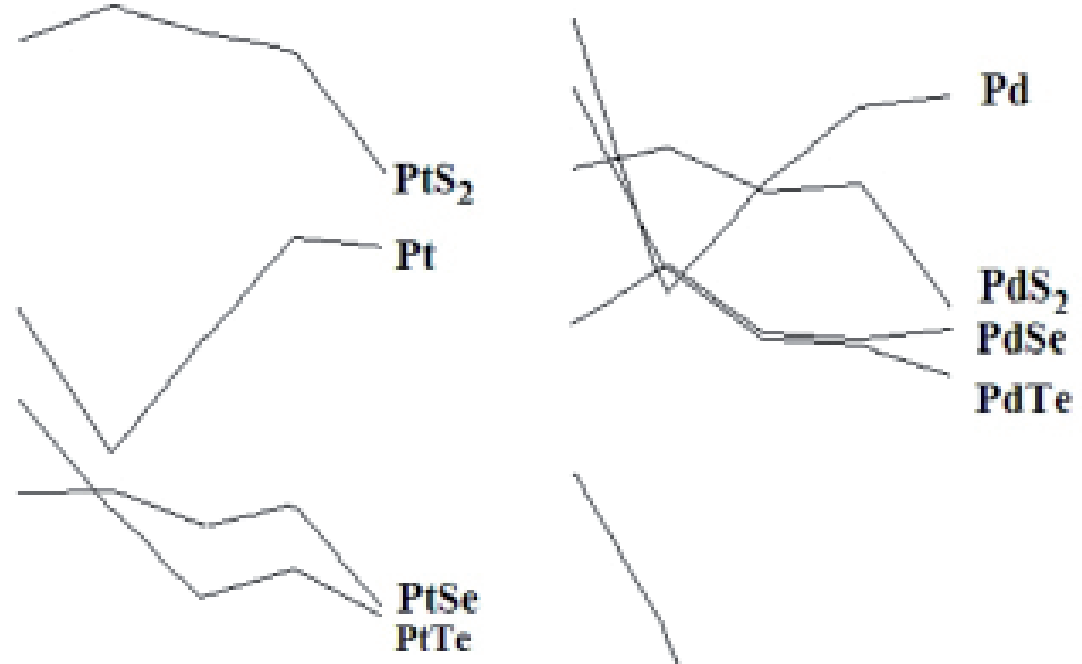

$-9$

$-10$

PtSe
PtTe

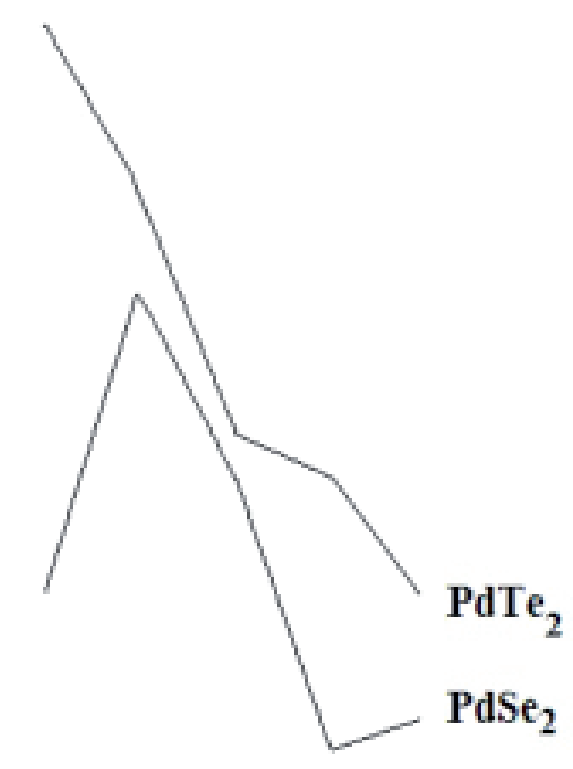

$-14$

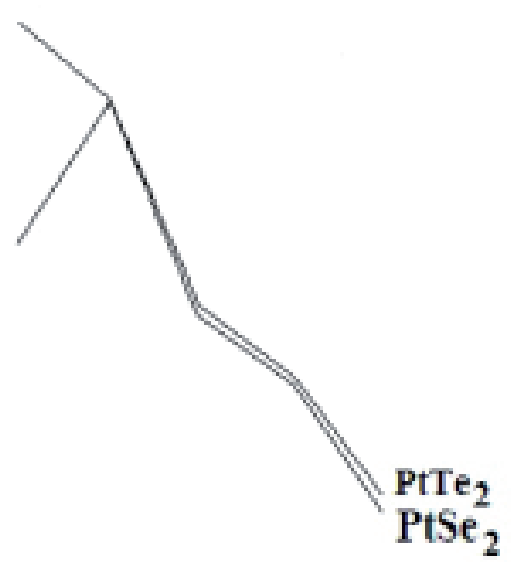

Рис. 4. Поведение селенидов и теллуридов платиноидов в процессе метаморфизма.

1-5 - минеральные парагенезисы: 1 -Pl-Cum; 2 - Pl-Act; 3 - Pl-Act-Ts; 4 - Pl-Hbl; $5-P l-A c t-C h l$.

Преобразование пород с более поздними плагиоклаз-роговообманковым парагенезисами (P1-Hbl №4) протекало при температуре $473{ }^{\circ} \mathrm{C}$ и давлении 4.3 кбар, а последующее образование диавторированных пород (Pl-Act-Chl № 5) при температуре $370{ }^{\circ} \mathrm{C}$ и давлении 1.16 кбар.

Физико-химическими модельными исследованиями установлено, что при достижении определенной величины парциального давления кислорода компонентный состав мультисистемы претерпевает некоторые изменения. Полученная информация о компонентном составе твердой фазы и флюида для различных стадий метаморфизма подробно представлена на рисунках (рис. 4 и 5 ). 


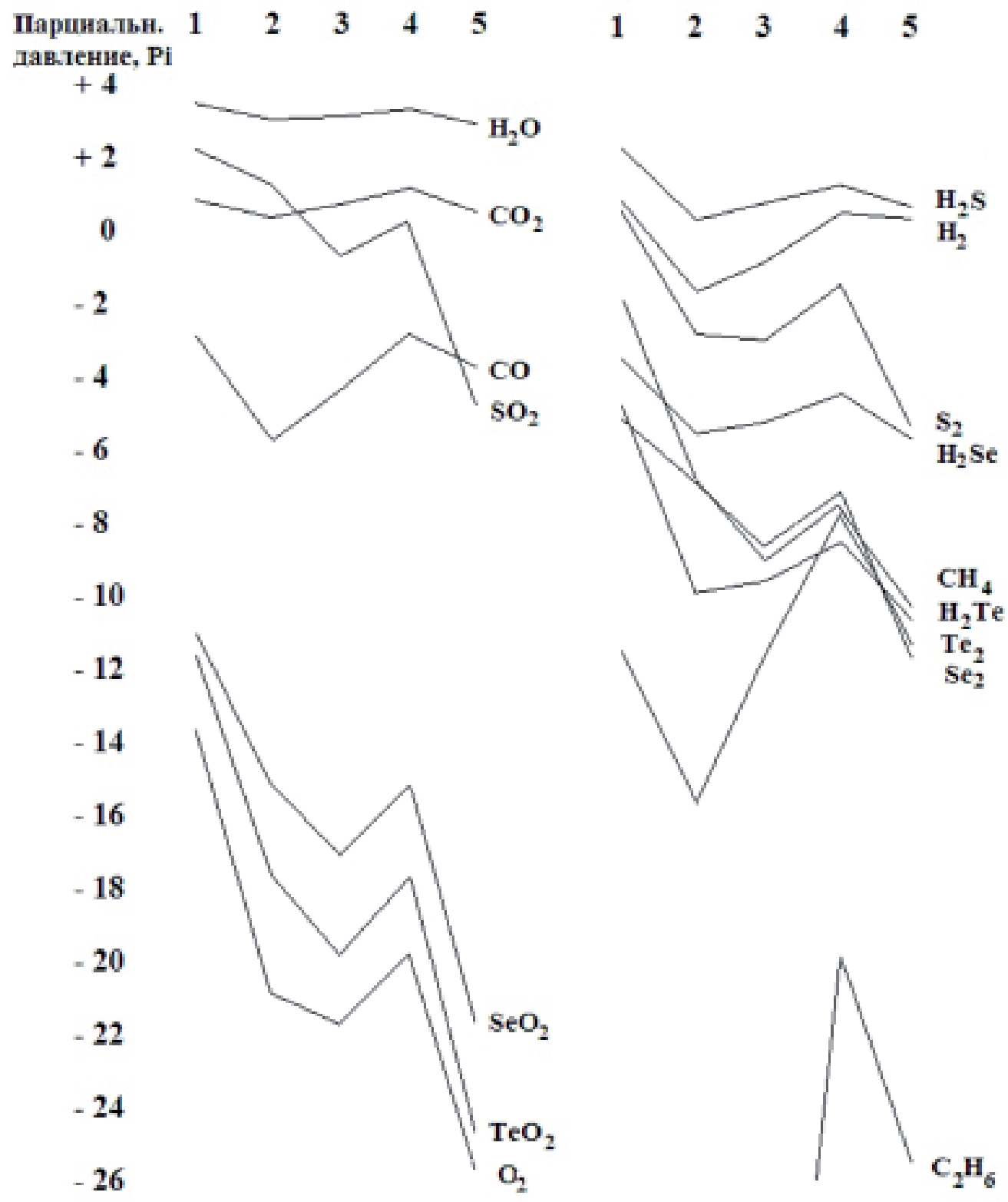

Рис. 5. Поведение компонентов флюида в прочессе метаморфизма.

1-5 - минеральные парагенезисы: 1 - Pl-Cum; 2 - Pl-Act; 3 - Pl-Act-Ts; 4 - Pl-Hbl; 5 - Pl-Act-Chl.

Действительно существование зоны резкой смены окислительных условий на восстановительные оказывает определенное влияние на состав флюида и твердой фазы элементов платины, палладия и их халькогениды. Кроме того, из установленного интересного явления на определенной стадии метаморфизма (зеленосланцевой) при условии постоянного содержания серы в природной системе в составе ЭПГ присутствуют только элементы палладия, платины и их сульфиды, а дисульфиды исчезают. Как показали результаты исследования, для образования дисульфидов элементов платиновой группы на этом этапе метаморфизма требуется более высокая концентрация серы в природной системе.

Этот факт, как представляется, может являться одним из поисковых признаков. 
III. Эвдиалит $\mathrm{Na}_{12} \mathrm{Ca}_{6} \mathrm{Fe}_{3} \mathrm{Zr}_{3}\left[\mathrm{Si}_{3} \mathrm{O}_{9}\right]_{2}\left[\mathrm{Si}_{9} \mathrm{O}_{24}(\mathrm{OH})_{3}\right]_{2}$. Присутствие в эвдиалите значительного количества циркония, редкоземельных и других элементов для исследователя представляет определённый интерес с целью его использования в качестве перспективного минерального сырья для производства различных химических соединений и, соответственно, последующего использования как сырьё в промышленности.

По данным химического анализа концентрата эвдиалита был проведен расчёт его формульного выражения:

$$
\mathrm{Na}_{11} \mathrm{KCa}_{3} \mathrm{Mg}_{0.7} \mathrm{Sr}_{0.5} \mathrm{MnAl}_{2} \mathrm{Fe}_{2} \mathrm{Zr}_{2.7} \mathrm{Nb}_{0.1} \mathrm{TiSi}_{23} \mathrm{O}_{67.1}(\mathrm{OH})_{6} \text {. }
$$

Для описания термодинамических равновесий в теоретической модели разложения кислотами эвдиалита использована 15-ти компонентная мультисистема, которая содержала в своем составе следующие независимые компоненты (элементы) Si-Al-Fe-Ca-Mg-Na-K-Mn-Sr-Zr-Nb-H-Cl-Ti-O [8, 10]. Pacчетная матрица мультисистемы представлена 59 зависимыми компонентами (химические соединения) с жидкой фазой - водный раствор, свойства которого описаны растворенными частицами. В модели учтены наиболее важные растворенные формы элементов - катионы и анионы [10], в соответствии с используемой для разложения эвдиалита соляной кислотой ( $\mathrm{HCl} 37$ мас. \%).

При этом одновременно учитываются возможные реакции окислениявосстановления, растворения, гидролиза, комплексообразования, ионного обмена и т.д. При наличии в водном растворе компонентов с различной степенью окисления в создаваемую систему дополнительно вводится независимый компонент - заряд, т.к. система должна быть электронейтральной.

Из полученного предварительного расчётного материала следует, что эвдиалит растворим в воде и довольно хорошо разлагается соляной кислотой. Последующими детальными исследованиями установили некоторую характерную особенность влияния $\mathrm{HCl}$ на этот процесс. Так, с увеличением величины ж/тв, т.е. количества соляной кислоты в растворе, система претерпевает смещение по координате $\mathrm{pH}$ в сторону снижения, в кислую область, a значения Eh соответствуют восстановительной среде. Окислительновосстановительный потенциал является термодинамической характеристикой, которая зависит от химического состава и соотношения концентраций окисленной и восстановленной форм вещества.

В составе раствора из компонентов, содержащих цирконий, установлена значительная концентрация оксихлорида циркония $\left(\mathrm{ZrOCl}_{2}\right)$, хлорионов циркония $\left(\mathrm{ZrCl}_{2}^{+2}, \mathrm{ZrCl}^{+3}\right)$ и $\mathrm{Zr}^{+4}$. Содержание последних ионов имеют как прямую, так и обратную корреляцию с концентрацией соляной кислоты. В растворе отмечается значительная концентрация хлоридов натрия, калия, магния, кальция и железа, равновесных с их хлорионами. Из кремнийсодержащих компонентов в растворе прослеживается высокая концентрация только положительного иона ортокремнёвой кислоты. Соединение ниобия в виде компонента $\mathrm{Nb}(\mathrm{OH})_{5}$ установлено только в растворе. В продуктах исследуемого процесса твёрдая фаза представлена диоксидом кремния, цирко- 


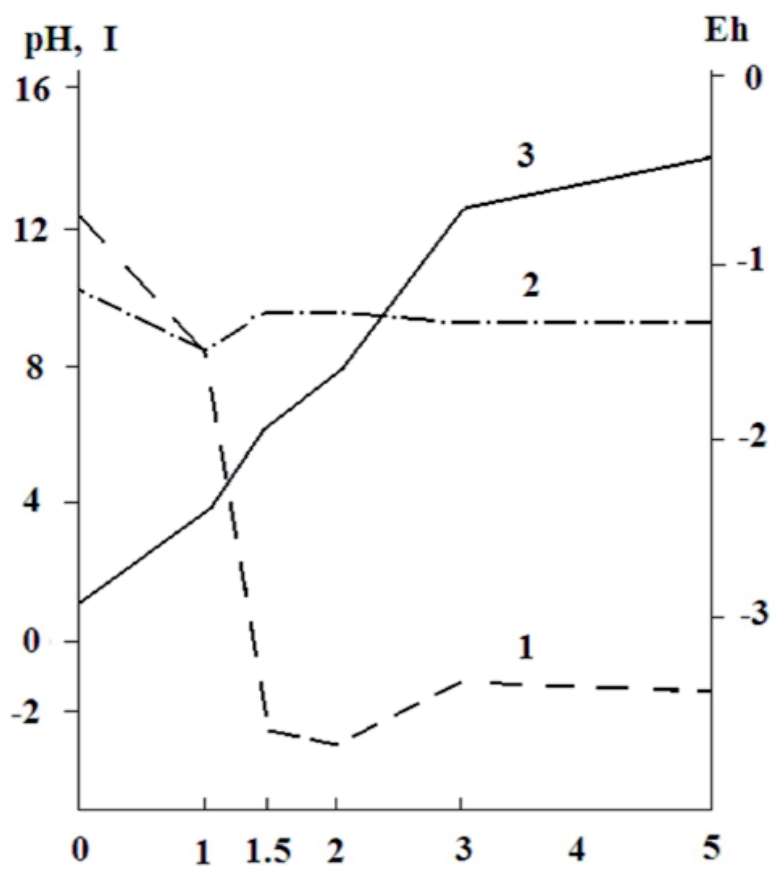

Рис. 6.Зависимостькислотно-основных свойств, рН (1), окислительно-восста3 новительного потенциала, Еh (2) и ионной сильы раствора, I (3) при разложении эвдиалита соляной кислотой в зависимости от величины отношения ж/тв.

ном, диоксидом и хлоридом титана, а также гидроксидхлоридом марганца и хлоридом стронция равновесного с его ионом $\mathrm{Sr}^{+2}$ в жидкой фазе.

Следует отметить несколько неожиданное влияние 1.5-2 кг соляной кислоты на процесс разложения 1 кг эвдиалита. В растворе отмечается резкое возрастание содержания $\mathrm{HCl}$, что сопровождается скачком величин $\mathrm{pH}$ и $\mathrm{Eh}$ (рис. 6). Этот факт нашел отражение в продуктах разложения эвдиалита снижение в растворе содержания: $\mathrm{CaCl}^{+}, \mathrm{FeCl}^{+}, \mathrm{K}^{+}, \mathrm{Na}^{+}, \mathrm{MgCl}^{+}, \mathrm{Sr}^{+2}$ и увеличение (почти на порядок) концентрации $\mathrm{ZrCl}_{2}^{+2}$, а в составе твердой фазы возросло содержание диоксида кремния, и исчез циркон $\left(\mathrm{ZrSiO}_{4}\right)$. Анализ результатов процесса разложения эвдиалита соляной кислотой показал, что увеличение отношения в системе ж/тв не способствовало заметному воз-

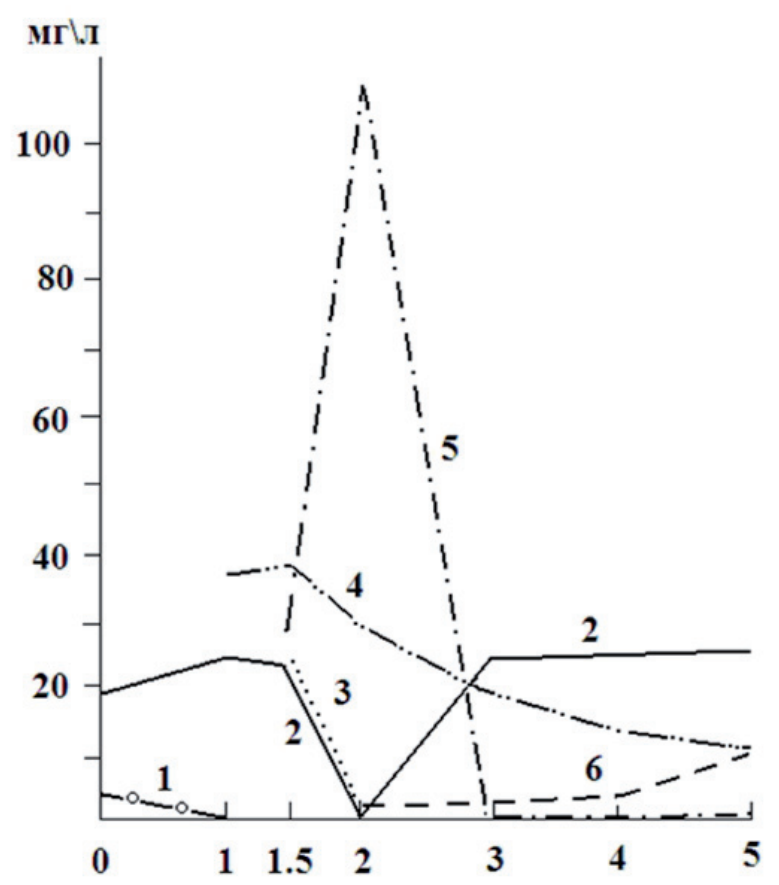

Рис. 7. Изменение содержания продуктов разложения эвдиалита соляной кислотой в зависимости от величинь отношения ж/тв:

$1-\mathrm{HZrO}_{3}^{-}, 2-\mathrm{ZrSO}_{4}$ (вес. \%),

$3-\mathrm{Zr}^{+4}(x \mathrm{10}), 4-\mathrm{ZrOCl}_{2} \cdot 10^{-3}$, $5-\mathrm{ZrCl}_{2}^{+2} \cdot 10^{-3}, 6-\mathrm{ZrCl}^{+3}$. 


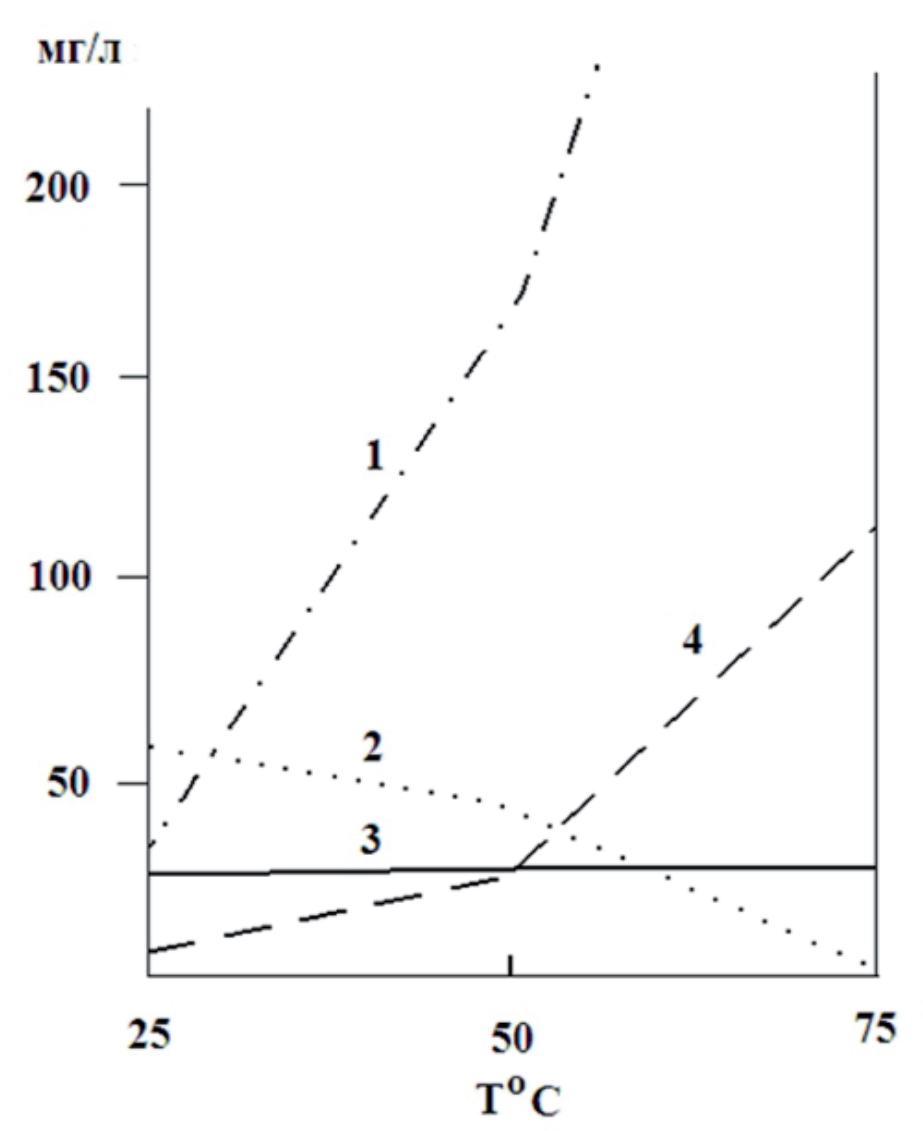

Рис. 8. Влияние температуры на концентрацию компонентов - продуктов разложения эвдиалита соляной кислотой (ж/mв = 3):

$1-\mathrm{ZrCl}_{2}^{+2}, 2-\mathrm{MgCl}^{+}, 3-\mathrm{ZrSiO}_{4}$ (мас. \%), 4- $\mathrm{ZrCl}^{+3}$.

растанию концентраций твердых продуктов и многих компонентов жидкой фазы (рис. 7, 8).

1. В процессе разложения эвдиалита соляной кислотой образуется твердая фаза, в составе которой установлены: $\mathrm{ZrSiO}_{4}, \mathrm{TiO}_{2}, \mathrm{TiCl}_{2}, \mathrm{MnOHCl}_{2} \mathrm{SiO}_{2}$ и $\mathrm{SrCl}_{2} \cdot \mathrm{H}_{2} \mathrm{O}$.

2. В жидкой фазе продуктов разложения эвдиалита присутствует значительная концентрация $\mathrm{ZrOCl}_{2}$, хлорионов циркония $\mathrm{ZrCl}_{2}^{+2}$ и $\mathrm{ZrCl}^{+3}$, а также следовое содержание ионов $\mathrm{Zr}^{+4}, \mathrm{ZrO}^{+2}$. Содержание последних ионов непосредственно коррелирует с содержащейся в системе соляной кислоты. В жидкой фазе установлено присутствие значительной концентрации ионов орто-кремниевой кислоты.

3. Хлориды натрия, калия и хлорсодержащие ионы железа, кальция и магния в жидкой фазе находятся в равновесном состоянии с ионами натрия, калия и хлора.

4. Среди продуктов разложения эвдиалита ниобий, в виде компонента $\mathrm{Nb}(\mathrm{OH})_{5}$, и ионы алюминия присутствует только в жидкой фазе.

5. Высокое содержание иона стронция $\left(\mathrm{Sr}^{+2}\right)$ в жидкой фазе равновесно c $\mathrm{SrCl}_{2} \cdot \mathrm{H}_{2} \mathrm{O}$ (твердая фаза) только при определенном отношении жидкости (соляная кислота) к твердому (эвдиалит). 
6. Изменение стандартных условий процесса разложения эвдиалита за счет повышения температуры в реагирующей системе практически оказало незначительное влияние на состав и содержание образующихся твердых продуктов.

7. Полученный расчетный материал позволяет считать нецелесообразным использование для разложения эвдиалита больших величин отношения жидкости (соляная кислота) к твердому (эвдиалит).

IV. Кианит $\mathrm{Al}_{2} \mathrm{SiO}_{5}$. Из литературных источников известно, что используя электротермический метод для переработки кианита, его можно считать прекрасным сырьем для производства алюминия и алюминиевых сплавов и широкого применения высокоглиноземистых кианитовых огнеупоров в металлургических процессах [13].

В данной работе исходный объект исследования рассматривается как однородно реагирующее вещество с восстановителем (углерод) в широком интервале температур в условиях равновесия в исследуемой системе. Цель таких исследований - используя методы численного моделирования оценить оптимальные условия получения определённых продуктов при переработке природного сырья. В процессе исследования предусмотрено определять предельные равновесные характеристики процесса через выход продукта для заданных условий. По результатам проведённого исследования можно оценить оптимальные варианты (условия) переработки исходного минерального сырья.

С целью использования математического моделирования для оценки условий переработки минерального сырья в присутствии углерода, кианит рассматривался в виде его теоретической формулы. Установлено, что разложение кианита при всех используемых в экспериментах концентрациях углерода осуществлялось в районе $450^{\circ} \mathrm{C}[8,10]$. По результатам теоретического физико-химического моделирования данного процесса были установ-

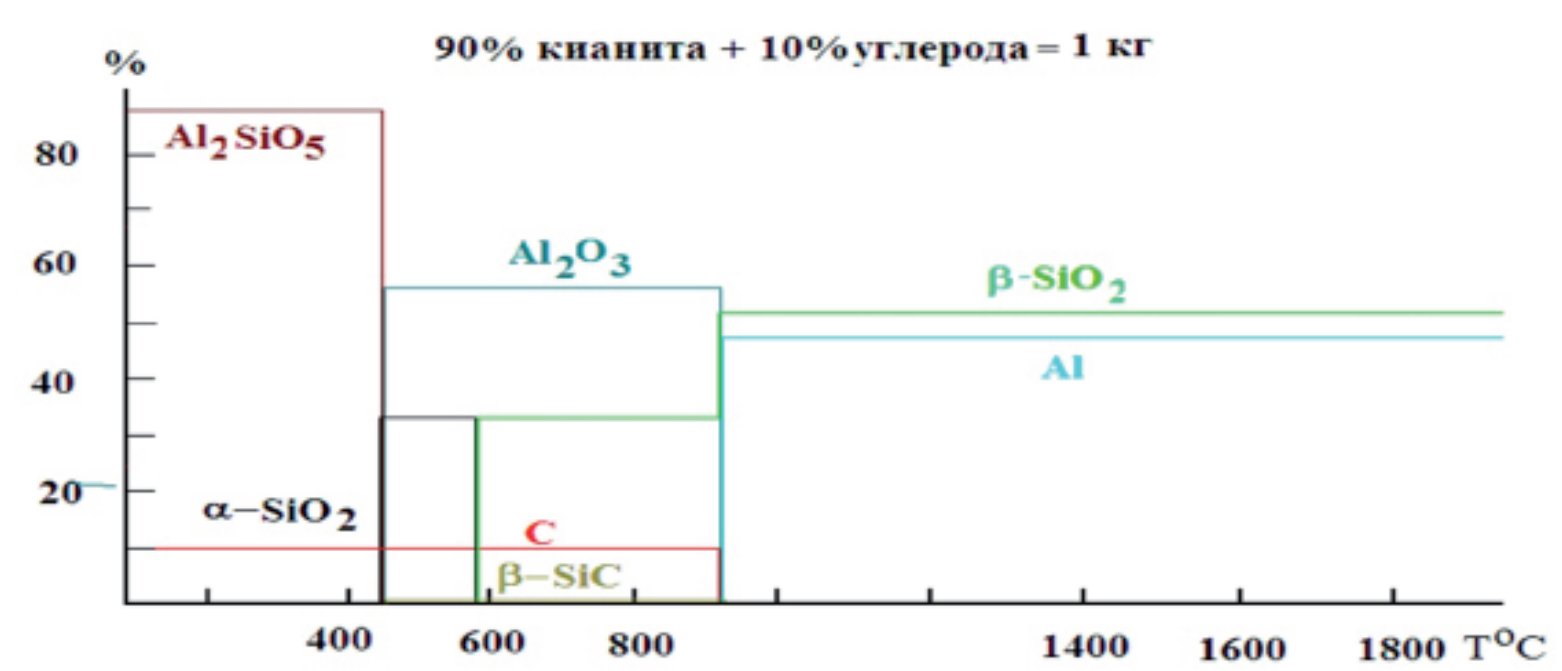

Рис. 9. Температура образования продуктов разложения $\left(\mathrm{Al}_{2} \mathrm{SiO}_{5}\right)$ nри $\mathrm{Al}_{2} \mathrm{SiO}_{5} / \mathrm{C}=10$. 


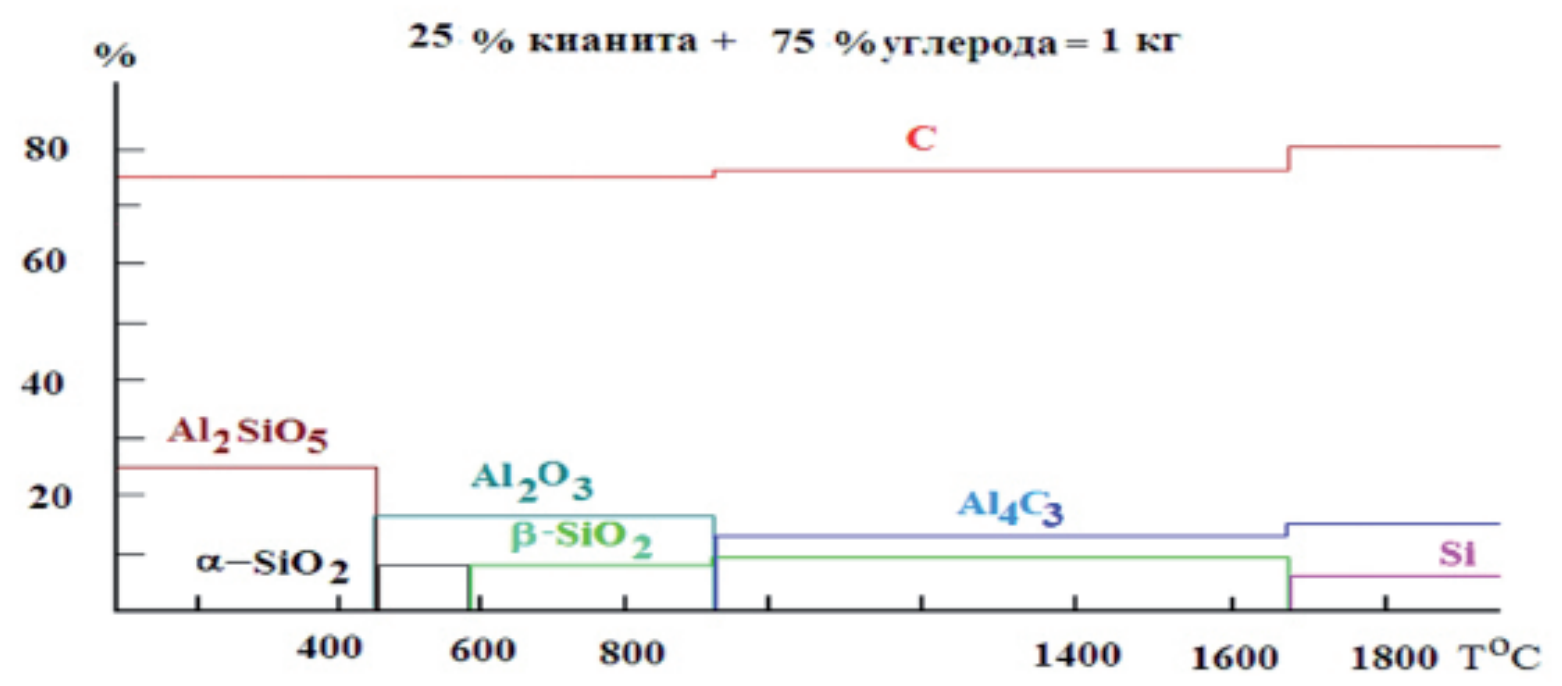

Рис. 10. Температура образования продуктов разложения $\left(\mathrm{Al}_{2} \mathrm{SiO}_{5}\right)$ nри $\mathrm{C} / \mathrm{Al}_{2} \mathrm{SiO}_{5}=3$.

лены три температурных «барьера» последовательного преобразования одних продуктов разложения кианита углеродом в другие продукты:

1. $575^{\circ} \mathrm{C}$. Температура превращения $\alpha-\mathrm{SiO}_{2}$ в $\beta-\mathrm{SiO}_{2}$. В присутствии углерода $\beta-\mathrm{SiO}_{2}$ с повышением температуры подвергается частичному разложению.

2. $926^{\circ} \mathrm{C}$. При данной температуре и концентрации углерода $10-50 \%$ в системе, корунд $\mathrm{Al}_{2} \mathrm{O}_{3}$ разлагается до алюминия и карбида алюминия $\mathrm{Al}_{4} \mathrm{C}_{3}$. Вероятность образования и существования последнего имеет место и в области высоких температур.

3. $1692^{\circ} \mathrm{C}$. В зависимости от концентрации углерода данная температура является температурой разложения $\beta-\mathrm{SiO}_{2}$ и $\mathrm{Al}_{4} \mathrm{C}_{3}$ до $\mathrm{Si}$ и $\mathrm{Al}$.

Из результатов численного моделирования следует, что состав используемых смесей и температура являются определяющими на образование продуктов разложения кианита (рис. 9, 10). В результате проведенного исследования процесс разложения кианита в присутствии углерода можно представить в виде следующей схемы:

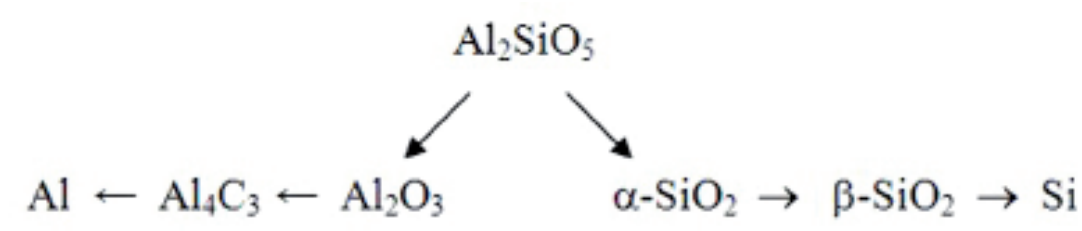

Из данных полученного расчетного материала следует, что конечными продуктами разложения кианита являются алюминий и кремний переменной концентрации (в зависимости от содержания углерода в смеси). Поэтому в продуктах термического разложения кианита не исключена возможность образования твердого раствора (силумин) разного состава. 


\section{Заключение}

Нам неизвестны более ранние исследования термодинамической истории образования платиноносных расслоенных интрузивов, и связанной с ней флюидной эволюцией в контексте формирования платинометальной минерализации. В данной работе нами показано, в краткой форме, возможности применения методов математического моделирования с целью получения результатов, достаточных для оценки протекания рудообразующих природных процессов.

На конкретных результатах численного моделирования показана целесообразность предварительной теоретической проработки любой планируемой экспериментальной работы. В качестве примера рассмотрены примеры химико-технологической переработки некоторых видов минерального сырья. Такой подход позволит, например, значительно снизить затраты на поиски оптимальных (экспериментальных) путей переработки минерального сырья. Вычислительный эксперимент обходится дешевле, чем проведение лабораторного реального процесса. Такой подход к решению проблемы легко управляем, и даёт возможность теоретически прогнозировать поведение объектов в неизвестных ситуациях.

Поэтому одной из внутренних задач данной работы является дальнейшее более интенсивное использование общей методологии экспериментального и математического моделирования подобных систем с использованием вычислительной техники.

\section{Список литературы}

1. Волошина 3.М., Каржавин В.К.Термодинамические условия и флюидный режим региональнометаморфизованных осадочно-вулканогенных толщ Печенгской структурной зоны. Отечественная геология. 2006. № 3. С. 53-57. 2. Зельдович Я.Б. О единственности решения уравнений закона действующих масс. Журн. Физ. химии. 1938. Т. 11. Вып. 5. С. 685-687.

3. Зельдович Я.Б., Овчинников А.А. Асимптотика приближения к равновесию и флуктуация концентрации // Письма в ЖЭТФ. 1977. Т. 26. С. 588-591. 4. Казьмин Л.А., Халиуллина О.А., Карпов И.К. Расчет химических равновесий поликомпонентных гетерогенных систем методом минимизации свободной энергии // Информ. Бюл. Алгоритмы и программы. ВНТИЦ. 1975. № 3. С. 18-19.

5. Каржавин В.К. Физико-химическое моделирование на ЭВМ процесса получения плавленых магниевых фосфатов. Комплексное использование минерального сырья. 1992. № 9. С. 48-54.

6. Каржавин В.К., Волошина 3.М. Моделирование гетерогенных равновесий при метаморфизме основных пород Печенгской структурной зоны. Зап. BMO. 2002. Ч.СХXXI. № 3. С.45-50.

7. Каржавин В.К., Волошина 3.М. Модельные исследования условий метаморфизма и флюидного режима рудоносного горизонта Панского массива в связи с ЭПГ оруденением. Геохимия. 2006. № 5. С. 522-531. 
8. Каржавин В.К. Термодинамическое моделирование сернокислого разложения эвдиалита / XVI Международная конференция по химической термодинамике в России. Т. 1. Суздаль, 1-6 июля, RCCT 2007 (тезисы). Москва (МГУ). 2007. С.73.

9. Каржавин В.К. Физико-химическое исследование процесса высокотемпературного разложения кианита // Проблемы освоения кианитовых месторождений Кольского полуострова, Карелии и Урала. Материалы Всероссийского совещания, посвящённого 80-летию Кольского НЦ РАН. Апатиты: Изд-во К \& М, 2010. С.78-86.

10. Каржавин В.К. Термодинамические величины химических элементов и соединений. Примеры их практического применения. Апатиты: Изд-во Кольского научного центра РАН, 2011. 160 с.

11. Карпов И.К. Физико-химическое моделирование на ЭВМ в геохимии. Новосибирск: Наука, 1981. 248 с.

12. Лурье Ю.Ю. Справочник по аналитической химии. М., 1979. С. 101.

13. Щипцов В.В. Кианит - эффективное сырьё для производства огнеупоров, сферы потребления, производители и мировая торговля // Новые огнеупоры. № 8. 2005. С. 78-82.

14. Berman R.G. Thermobarometry using multi-equilibrium calculations: a new technique, with petrological applications // Canad. Miner. 1991. V. 29. N 4. P. 833-855.

\section{НОВЫЙ МЕТОД РЕКОНСТРУКЦИИ ОБСТАНОВОК ФОРМИРОВАНИЯ ПРОТОЛИТОВ ДРЕВНЕЙШИХ КОМПЛЕКСОВ}

Марчук T.C. ${ }^{1}$, Мартынов Е.В. ${ }^{2}$

https://doi.org/10.31241/MIEN.2018.14.23

${ }^{1}$ Апатитский филиал Мурманского государственного технического университета, Апатиты, marchuk@geoksc.apatity.ru

${ }^{2}$ Геологический институт КНЦ РАН, Апатиты

В данной работе описывается подход к реконструкции геодинамических обстановок формирования комплексов докембрия и фанерозоя, основанный на геохимических данных и определяющий достаточно высокую надежность результатов реконструкции. Кольский регион является хорошим полигоном для получения разнообразных данных по реконструкции геодинамических обстановок. Информационной основой исследований является имеющаяся в распоряжении авторов совокупность баз данных по вещественному составу образований докембрия (банк данных «Тиетта») и фанерозоя (литературные данные). Всего было использовано более 20000 полных силикатных анализов. Методологической основой является работа с базой данных, систематизация и сопоставление материалов по геологии, ве- 